\title{
Correction to: Sibling Bullying in Turkish Adolescents: Translation and Cross-Cultural Validation of the Sibling Bullying Questionnaire
}

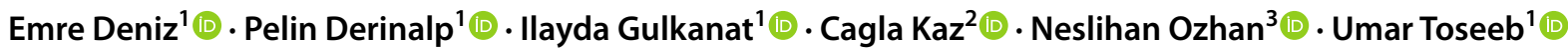

Published online: 29 January 2022

(c) Springer Science+Business Media, LLC, part of Springer Nature 2022

\section{Correction to: Journal of Family Violence} https://doi.org/10.1007/s10896-022-00360-2

The originally published version of this article unfortunately contained some mistakes. The ethical statement was blinded as follows:

Ethical approval for the study was granted by the Department of Education Ethics Committee, University of Blinded (Ref: Blinded.).

The ethical statement of the study has now been corrected as follows:

Ethical approval for the study was granted by the Department of Education Ethics Committee, University of York (Ref: FC20/1).

The original article has been corrected.

Publisher's Note Springer Nature remains neutral with regard to jurisdictional claims in published maps and institutional affiliations.

The original article can be found online at https://doi.org/10.1007/ s10896-022-00360-2.

Emre Deniz

emre.deniz@york.ac.uk

1 Department of Education, University of York, York YO10 5DD, UK

2 Department of Politics, University of York, York YO10 5DD, UK

3 Department of Psychology, University of Southampton, Southampton SO17 1PS, UK 